\title{
Turner's Syndrome: Approach to Diagnosis and Treatment
}

\author{
Sadhana Sah, Ganesh Dangal, Aruna Karki, Hema Pradhan, Ranjana Shrestha, Kabin Bhattachan, \\ Rekha Poudel, Nishma Bajracharya, Umesh Jha, Kenusha Tiwari, Sonu Bharati
}

Department of Obstetrics and Gynecology, Kathmandu Model Hospital, Kathmandu, Nepal

Received: 20 November 2018; Accepted: 12 December 2018

DOI: 10.3126/njog.v13i3.23476

\section{ABSTRACT}

Turner's syndrome is the most common karyotypic abnormality causing gonadal failure and primary amenorrhea. It is characterized by short stature and absence of secondary sexual characteristics. It is diagnosed by increased plasma FSH and LH level with low level of estrogen i.e. hypergonadotrophic hypogonadism. Ultrasound abdomen reveals streak ovaries and atrophic uterus. Karyotype confirms the diagnosis of Turner's syndrome (45X)

We present here a 15 years girl who presented with primary amenorrhea with short stature with breast development corresponds to Tanner stage I. Her FSH was raised. Ultrasound abdomen showed uterine agenesis and streak ovaries. Karyotype showed $45 \mathrm{XO}$ which confirmed the diagnosis of Turner's syndrome. She is now on estrogen therapy and her height has increased and breast development corresponds to Tanner stage II

Keywords: hypergonadotrophic hypogonadism, primary amenorrhea, Turner's syndrome.

\section{INTRODUCTION}

Turner's syndrome is the most common karyotypic abnormality causing gonadal failure and primary amenorrhea. Amenorrhea is the result of accelerated atresia of the follicles. There are stigmata with Turner's syndrome that include short stature, webbed neck, shield chest, cubitus valgus (increased carrying angle of the arms), low hair line, high arched palate, multiple pigmented nevi, and short fourth metacarpals. ${ }^{1}$ It is a condition characterized by complete or partial absence of second sex chromosome. Approximately 1 in 2000 to 1 in 5000 female live born phenotypic females are affected ${ }^{2}$

\section{CASE}

A 15 years girl from Kathmandu presented to outpatient department of Kathmandu Model Hospital with complaint of absence of menses till 15 years of age. On clinical examination, she was thin built. She weighed $34 \mathrm{~kg}$ and was 4 feet tall. Her vital parameters were normal. Her breast examination showed Tanner stage I with absence of axillary and pubic hair. Her vaginal length was $2 \mathrm{~cm}$. On ultrasonography, uterine morphology was not seen, tiny hypoechoic linear band was noted, most likely uterine agenesis. Right

\section{CORRESPONDENCE}

Dr. Sadhana Sah

Department of Obstetrics and Gynecology

Paropakar Maternity and Women's Hospital, Thapathali,

Kathmandu, Nepal

Email: sadhanasah1005@gmail.com; Phone:+977- 9841533748 ovary was not visualized and left ovary was small in volume $(0.4 \mathrm{cc})$ [Figure-1]. Her FSH was raised (94.4 $\mu \mathrm{iu} / \mathrm{ml})$. Her karyotype showed 45XO [Figure-2].

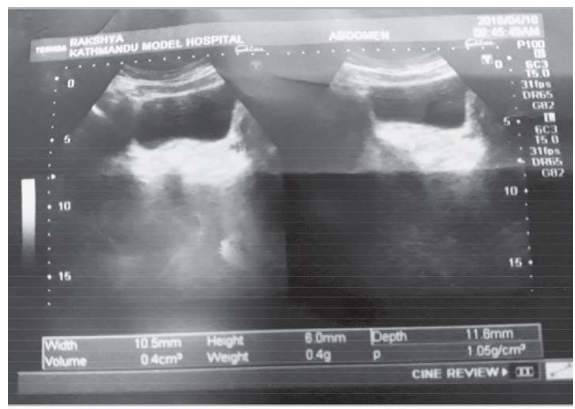

Figure 1: Ultrasound picture showing streak gonads.

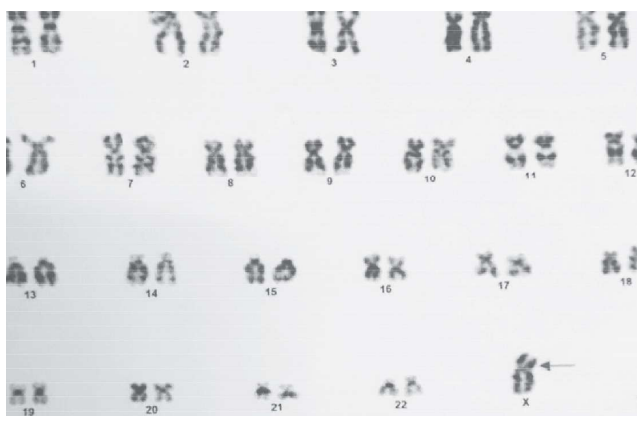

Figure 2: Genetic karyotype showing 45XO 
Her echocardiograpy was normal and other blood investigations were normal. She was advised for bone scan and it could not be done because of financial crisis. She was well counseled about her condition and treatment plan. She was started on estrogen therapy for 3 weeks and advised for follow up. During follow up, her breast development was Tanner stage II and her height was 4 feet 4 inches.

\section{DISCUSSION}

Turner's syndrome is characterized by primary amenorrhea and short stature with absence of secondary sexual characteristics. It represents the most common form of hypergonadotrophic hypogonadism. It is associated with cardiac defects such as non-stenotic bicuspid aortic valve, coarctation of aorta, aortic stenosis, mitral valve prolapse, renal defects such as pelvic kidney, horseshoe kidney, double collecting system, complete absence of one kidney and uteropelvic junction obstruction. ${ }^{3}$

Turner's syndrome is associated with constellation of potential abnormalities involving many organ system, making it challenging for health care provider and families. Short stature, ovarian dysgenesis and infertility are clinical hallmarks in majority of patients with Turner's syndrome. The incidence of spontaneous puberty in Turner's syndrome is reported to be one third. Genes located on proximal region of long arm of $\mathrm{X}$ chromosome are important for normal ovarian function and development and haploinsufficiency of these genes is thought to be implicated in the pathogenesis of gonadal dysgenesis associated with Turner's syndrome. Abnormalities in the hypothalamic feedback system with increased level of gonadotropins to compensate for blunted ovarian function or FSH surge commonly seen in Turner's syndrome before the ovarian failure have been hypothesized. ${ }^{4}$

Key aspect of management of Turner's syndrome in children are cardiovascular monitoring and treatment of congenital heart disease, growth hormone therapy to augment linear growth and supplemental estrogen therapy for sexual development and preservation of bone mineral density. The mean adult height in Turner's syndrome is $140 \mathrm{~cm}$ but with growth hormone and estrogen therapy, the average height increases to $150 \mathrm{~cm}$. Growth hormone therapy is discontinued after the patient reaches to bone age of 14 years, sex hormone therapy is generally continued throughout life. Spontaneous menstruation and childbirth occurs in 2 to $5 \%$ of patient. Because spontaneous pregnancy occurs, patient should be counselled about birth control if sexually active. In-vitro fertilization is being studied in patient with Turner's syndrome. Spontaneous and assisted pregnancy carries substantial risk. Preconceptional counseling and echocardiography and cardiac MRI are essential. ${ }^{5}$ Recombinant human growth hormone replacement therapy with estrogen replacement with psychosocial support are mainstay of treatment. 3 Our patient had primary amenorrhea, short stature and absence of secondary sexual characteristics. On further evaluation, her FSH was raised with karyotypic abnormality $45 \mathrm{XO}$. She has been well counselled about her condition. She was then started on estrogen therapy for 3 months and advised for follow up. Our plan is to continue estrogen therapy till menarche is achieved and secondary sexual characteristics develop corresponding to Tanner stage IV. We have also planned to add progesterone and growth hormone therapy in further follow up.

\section{CONCLUSIONS}

A strong possibility of Turner's syndrome should be made if a female presents with primary amenorrhea, short stature and absence of secondary sexual characteristics. Timely diagnosis, monitoring of multisystem involvement, hormonal therapy and most importantly, psychosocial support form the mainstay of treatment.

\section{REFERENCES}

1. Berek J. Berek and Novak's Gynecology.15th ed. Philadelphia: Wolters Kluwer; 2015 .

2. Basnet S, Eleena A, Sharma AK. Turner SyndromeUncommonly Diagnosed Cause of Short Stature: Case Report and Review of Literature. J Nepal Paediatr Soc. 2013;33(1):74-6.

3. Gupta RK, Gupta R, Sharma SD. Turner Syndrome. Journal of
Medical Education \& Research. 2006;8:219-21

4. Improda N, Rezzuto M, Alfano S, Parenti G, Vajro P, Pignata $\mathrm{C}$, et al. Precocious puberty in Turner Syndrome: report of a case and review of the literature. Italian Journal of Pediatrics. 2012;38(1):54.

5. Noor M, Abdullah S, Mahmood S. Turner's Syndrome. Gomal Journal of Medical Sciences. 2007;30:5(1). 